Robert A. Hegele $\cdot$ Stewart B. Harris

Anthony J.G. Hanley $\cdot$ Fang Sun • Philip W. Connelly

Bernard Zinman

\title{
-6A Promoter variant of angiotensinogen and blood pressure variation in Canadian Oji-Cree
}

Received: October 17, 1997 / Accepted: November 13, 1997

\begin{abstract}
We previously reported significant associations between variation in the $A G T$ gene at codon 235 and both systolic pressure and hypertension in Canadian Oji-Cree. Recently, Inoue et al suggested that the $A G T$ T235 variant was not causative, but was rather in linkage disequilibrium with a variant in the $A G T$ promoter, namely $-6 \mathrm{~A}$, that was associated with increased in vitro expression of angiotensinogen and was thus a strong candidate to be the functional basis of the previously observed associations. We genotyped 518 adult Oji-Cree for the $A G T$ promoter polymorphism and tested for its association with blood pressure and hypertension. We found that the frequency of the $-6 \mathrm{~A}$ variant was 0.85 in the Oji-Cree, which is much higher than the frequency observed in other human samples. We also found strong linkage disequilibrium between the $A G T-6 \mathrm{~A}$ and T235 variants. However, genetic variation of the $A G T$ promoter was only marginally associated with variation in systolic pressure, with a trend to significantly higher systolic pressure seen in $A G T-6 \mathrm{~A} / \mathrm{A}$ homozygotes than in subjects
\end{abstract}

R.A. Hegele $(\bowtie)^{1} \cdot$ F. Sun $\cdot$ P.W. Connelly

St. Michael's Hospital, Toronto, Ontario, Canada

R.A. Hegele · P.W. Connelly $\cdot$ B. Zinman

Department of Medicine, University of Toronto, Toronto, Ontario, Canada

R.A. Hegele $\cdot$ P.W. Connelly

Department of Clinical Biochemistry, University of Toronto,

Toronto, Ontario, Canada

P.W. Connelly

Department of Biochemistry, University of Toronto, Toronto, Ontario, Canada

\section{S.B. Harris}

Thames Valley Family Practice Research Unit, University of Western Ontario, London, Ontario, Canada

A.J.G. Hanley · B. Zinman

Samuel Lunenfeld Research Institute, Mount Sinai Hospital, Toronto, Ontario, Canada

${ }^{1}$ Present address: Blackburn Cardiovascular Genetics Laboratory, Robarts Research Institute, 406-100 Perth Drive, London, Ontario, Canada N6A 5K8

Tel. +1-519-663-3461; Fax +1-519-663-3789

e-mail: robert.hegele@rri.on.ca with other genotypes. In addition, genetic variation of the $A G T$ promoter tended to be associated with a diagnosis of hypertension. Despite the very high prevalence of $-6 \mathrm{~A}$, our native sample was essentially normotensive. Our findings are consistent with a marginally deleterious effect of the $A G T-6 \mathrm{~A}$ allele on blood pressure, but linkage disequilibrium with another causative variant cannot be ruled out in this sample of aboriginal Canadians.

Key words Atherosclerosis - Hypertension - Gene expression $\cdot$ Linkage disequilibrium $\cdot$ Small genetic effects

\section{Introduction}

There have been many reported associations between hypertension-related phenotypes and DNA markers of candidate genes (Williams et al. 1994). However, alleles of very few genes are consistently related to intermediate phenotypes across diverse populations (Williams et al. 1994). Part of the inconsistency may relate to the fact that most DNA markers studied so far do not have a functional impact on the structure or expression of the gene product. Thus, most reported genetic associations have been attributed to linkage disequilibrium with putative functional changes elsewhere at the genetic locus. Since this may vary between populations, factors such as admixture can result in false conclusions about genetic associations. One strategy to reduce such confounding in association studies may be to select DNA markers that are proven, by various assays, to directly mark a functional change in the gene of interest.

DNA markers of the angiotensinogen gene $(A G T)$ have been associated with variation in plasma angiotensinogen levels and blood pressure (BP) in diverse study samples (Jeunemaitre et al. 1992; Rotimi et al. 1994; Hata et al. 1994; Bloem et al. 1995). Furthermore, experiments in transgenic mice indicated that overexpression of human angiotensinogen caused profound hypertension (Kim et al. 1995). Recently, a haplotype comprised of the T235 allele and the $-1074 \mathrm{~T}$ variant was found to be associated with higher 
serum angiotensinogen concentrations in blacks and whites (Bloem et al. 1997).

However, the best candidate for the functional basis for the numerous associations between $A G T$ and $\mathrm{BP}$ is a common genomic variant of the $A G T$ promoter, namely $-6 \mathrm{~A}$ using the nomenclature recommended by Beaudet and Tsui (1993), which was found to be in linkage disequilibrium with the most commonly associated $A G T$ marker in genetic association studies over the last five years, namely T235 (Jeunemaitre et al. 1992; Rotimi et al. 1994; Hata et al. 1994; Bloem et al. 1995). Recent, thorough, and extensive in vitro expression studies showed that $A G T-6 \mathrm{~A}$ was associated with $30 \%-70 \%$ higher $A G T$ gene expression compared with $A G T-6 \mathrm{G}$ (Inoue et al. 1997). A DNA marker for the $A G T-6$ A allele may therefore mark a functional DNA change that is more biologically relevant than the more commonly studied $A G T$ T235 polymorphism (Inoue et al. 1997).

We previously reported a significant association between the AGT T235 variant and both elevated systolic BP and hypertension in a sample of adult Canadian Oji-Cree (Hegele et al. 1997). As with other such genetic associations, we could not differentiate the potential direct effect on phenotype of the $A G T$ T235 allele from linkage disequilibrium with a putative functional marker. Given the recently demonstrated functional impact of the $A G T-6 \mathrm{~A}$ variant (Inoue et al. 1997), we postulated that the promoter variant would be associated with variation in BP in the OjiCree. We now report the results of an association analysis with BP using genotypes of the $A G T$ promoter as determined by a novel restriction isotyping method.

\section{Methods}

\section{Study subjects}

The isolated community of Sandy Lake, Ontario, is located about $2000 \mathrm{~km}$ northwest of Toronto, in the subarctic boreal forest region of central Canada. Historically, the ancestors of the contemporary residents of this region lived a nomadic, hunting-gathering subsistence typical of other native peoples of the northeastern subarctic. Since the development of the reservation and residential school systems, the lifestyle changed from very physically active to very sedentary. The primary source of food changed from wildlife with roots and berries to processed foods high in animal fats, which are supplied by a company store.

Of this community, 729 members aged 10 years and older participated in the present study (Hegele et al. 1997). Subjects answered a questionnaire for medical history, which included a question on the current use of antihypertensive drugs. Physical examination included determination of body mass index (BMI) defined as weight $/ \mathrm{height}^{2}\left(\mathrm{~kg} / \mathrm{m}^{2}\right)$ and two separate BP determinations in the right arm with the subject seated. Systolic BP was recorded to the nearest $2 \mathrm{mmHg}$ at the appearance of the first Korotkoff sound (phase I) and diastolic BP was recorded to the nearest
$2 \mathrm{mmHg}$ at the disappearance of the fifth Korotkoff sound (phase V). Blood samples were obtained with informed consent after a 10-h fasting period. Exclusion criteria included age below 18 years and a blood sample inadequate for completing all determinations. The project was approved by The University of Toronto Ethics Review Committee.

\section{Biochemical and genetic analyses}

Blood for lipoprotein analyses was centrifuged at 2000rpm for $30 \mathrm{~min}$ and the plasma was stored at $-70^{\circ} \mathrm{C}$. Fasting plasma concentrations of lipoproteins and apolipoproteins were determined as described (Hegele et al. 1994a,b, 1995a,b). Genotypes for $A G T$ codon 235 were previously determined (Hegele et al. 1997). A new restriction isotyping method was developed to determine genotypes of $A G T$ position $-6 \mathrm{nt}$. Briefly, $50 \mathrm{ng}$ of genomic DNA was amplified at an annealing temperature of $56^{\circ} \mathrm{C}$ using amplification primers 5'-AATAAGGCATCGTGACCC-3' and 5'ACCTTCTGCTGTAGTACC-3' to yield a 65-bp fragment that spanned the $A G T-6 \mathrm{~A} / \mathrm{G}$ variant site. Digestion of a polymerase chain reaction (PCR) product containing the $-6 \mathrm{~A}$ variant with $B s t \mathrm{NI}$ produced two fragments with sizes 45 and $20 \mathrm{bp}$. Digestion of a PCR product containing the $-6 \mathrm{G}$ variant with $B s t$ NI produced only a single fragment with size $65 \mathrm{bp}$. Digested PCR products were electrophoresed in $14 \%$ polyacrylamide gels and were visualized under ultraviolet light after staining with ethidium bromide. All samples were run with known genotypic controls.

\section{Statistical analysis}

The significance of deviations of observed genotype frequencies from those predicted by the Hardy-Weinberg equation were evaluated with chi-square tests. Linkage disequilibrium between the $A G T$ promoter and codon 235 markers was estimated using Hill and Robertson's correlation coefficient of gene frequencies (Hill and Robertson 1968).

SAS (Version 6.1) was used for all statistical comparisons (SAS Institute 1987). The distribution of systolic and diastolic BP was significantly nonnormal in this dataset; therefore, for parametric statistical analyses, each quantitative variable was transformed and subjected to analysis of normality as described (Hegele et al. 1994a,b, 1995a,b). Analysis of variance (ANOVA) was performed using the general linear models procedure to determine the sources of variation for systolic and diastolic BP, with $F$ tests computed from the type III sums of squares. This form of sums of squares is applicable to unbalanced study designs, and reports the effect of an independent variable after adjusting for all other variables included in the model (Hegele et al. 1994a,b, 1995a,b). Dependent variables were transformed systolic and diastolic BP. Independent variables were age, sex, the natural logarithm of BMI, and current treatment with an antihypertensive medication. Also included as an independent variable was the plasma concentration of 
apolipoprotein B (apo B), since this was previously shown to be significantly associated with variation in $\mathrm{BP}$ in the OjiCree (Hegele et al. 1997). Finally, the $A G T-6 \mathrm{~A} / \mathrm{G}$ genotype was also included as an independent variable. BP differences between individuals classified by genotype were compared using a $t$-test. In addition, association between $A G T-6 \mathrm{~A} / \mathrm{G}$ genotype and hypertension, defined as systolic BP greater than $140 \mathrm{mmHg}$ and/or diastolic BP greater than $90 \mathrm{mmHg}$ and/or current use of antihypertensive medication, was evaluated using chi-square analysis.

\section{Results}

Baseline phenotypes in whole sample

Sufficient DNA and phenotypic information was obtained from 518 adult subjects (57\% females). The mean \pm SD for the age, systolic BP, diastolic BP, and BMI were, respectively, $35.0 \pm 13.5$ years, $119.4 \pm 15.0 \mathrm{mmHg}, 68.3 \pm$ $11.4 \mathrm{mmHg}$, and $28.1 \pm 5.3 \mathrm{~kg} / \mathrm{m}^{2}$. Of these subjects, 40 took medication for hypertension; almost all of these took inhibitors of angiotensin converting enzyme.

\section{Allele and genotype frequencies}

The observed frequency of the $A G T-6 \mathrm{~A}$ allele was 0.852 , which was more than twice that reported in Caucasians (Jeunemaitre et al. 1992; Inoue et al. 1997). The observed genotype frequencies did not deviate from those predicted by the Hardy-Weinberg equation. Very strong, but not complete, linkage disequilibrium was observed between alleles of the $A G T-6 \mathrm{G} / \mathrm{A}$ and codon 235 genotypes $(r=0.83, P<0.0001)$, with -6 A occurring almost always on alleles that contained T235. The frequencies for the four $A G T$ haplotypes $-6 \mathrm{~A} / \mathrm{T} 235,-6 \mathrm{~A} / \mathrm{M} 235,-6 \mathrm{G} / \mathrm{T} 235$, and $-6 \mathrm{G} / \mathrm{M} 235$ were, respectively, $0.819,0.033,0.132$, and 0.015 .

Genetic of variation in systolic and diastolic BP

The results of the ANOVA are shown in Table 1. One ANOVA was performed each for systolic and diastolic BP. Since ANOVA takes multiple comparisons into account, we did not adjust the levels of nominal significance. For systolic $\mathrm{BP}$, a nonsignificant trend for association with $A G T$ $-6 \mathrm{~A} / \mathrm{G}$ genotype was seen $(P=0.11)$. For diastolic BP,
Table 1 Analysis of variance in Sandy Lake Ojibway-Cree

\begin{tabular}{|c|c|c|c|c|c|}
\hline & \multirow[b]{2}{*}{$D F$} & \multicolumn{2}{|c|}{$\log ($ systolic BP) } & \multicolumn{2}{|c|}{$\log ($ diastolic BP) } \\
\hline & & $F$ value & $P>F$ & $F$ value & $P>F$ \\
\hline Sex & 1 & 26.9 & $<0.0001$ & 12.6 & 0.0004 \\
\hline Age & 1 & 64.4 & $<0.0001$ & 0.97 & NS (0.33) \\
\hline Logarithm of BMI & 1 & 33.4 & $<0.0001$ & 28.2 & $<0.0001$ \\
\hline $\begin{array}{l}\text { Antihypertensive } \\
\text { treatment }\end{array}$ & 1 & 33.4 & $<0.0001$ & 7.42 & 0.0067 \\
\hline Logarithm of apo B & 1 & 1.4 & NS ( & 27.6 & $<0.0001$ \\
\hline$A G T-6 \mathrm{~A}$ genotype & 2 & 2.25 & NS (0.11) & 0.04 & NS (0.96) \\
\hline
\end{tabular}

BP, blood pressure; DF, degrees of freedom; BMI, body mass index; apo, apolipoprotein; $P>F$, probability of a greater between-group $F$ value using ANOVA; NS, not significant with nominal $P<0.05 ; A G T$, angiotensinogen gene.

there was clearly no significant association with $A G T-6 \mathrm{~A} /$ G genotype $(P=0.96)$. The ANOVA was performed using the $A G T-6 \mathrm{~A} / \mathrm{G}$ genotype, but the associations with the $A G T$ genotype at codon 235 and the $A G T$ haplotype constructed from these two genotypes showed similar levels of significance in separate post hoc analyses (data not shown).

The 12 homozygotes for the $A G T-6 \mathrm{G}$ allele and the 129 heterozygotes had the lowest systolic BP $(123.7 \pm 13.3$ and $123.4 \pm 16.4 \mathrm{mmHg}$, respectively) while the 377 homozygotes for the $A G T-6 \mathrm{~A}$ allele had the highest systolic $\mathrm{BP}$ $(126.0 \pm 15.4 \mathrm{mmHg})$. Pairwise comparisons showed a significant difference in systolic BP for homozygotes for the $A G T-6 \mathrm{~A}$ allele compared with the other genotypes $(P=0.033)$. None of the pairwise comparisons for diastolic BP indicated any significant difference between the genotypes (data not shown).

The frequency of the $A G T-6 \mathrm{~A}$ allele in those taking antihypertensive medications was 0.87 , which was not significantly different from the prevalence of 0.85 observed in those not taking antihypertensive medications (chisquare $=1.9, \mathrm{NS}$ ). In subjects with hypertension, the frequency of the $A G T-6 \mathrm{~A}$ allele was 0.89 , which was not significantly different from the prevalence of 0.84 observed in the subjects without hypertension (chi-square $=3.77$, $P=0.055)$.

\section{Discussion}

In this study of largely normotensive aboriginal Canadians, we found: (1) a very high prevalence of the $A G T$ $-6 \mathrm{~A}$ allele; (2) significant, but not complete, linkage

Table 2 Number (percent) of $A G T-6 \mathrm{~A} / \mathrm{G}$ genotypes in subsets of Sandy Lake Ojibway-Cree

\begin{tabular}{lcccc}
\hline Genotype & Normotensive & Hypertensive & No medication & $\begin{array}{l}\text { Antihypertensive } \\
\text { medication }\end{array}$ \\
\hline G/G & $11(2.8 \%)$ & $1(0.8 \%)$ & $11(2.3 \%)$ & $1(2.5 \%)$ \\
G/A & $104(26.4 \%)$ & $25(20 \%)$ & $120(25.1 \%)$ & $9(22.5 \%)$ \\
A/A & $278(70.7 \%)$ & $99(79.2 \%)$ & $347(76.2 \%)$ & $30(75.0 \%)$ \\
Totals & $393(100 \%)$ & $125(100 \%)$ & $478(100 \%)$ & $40(100 \%)$ \\
\hline
\end{tabular}


disequilibrium between $A G T-6 \mathrm{~A}$ and T235; (3) a nonsignificant trend towards association between variation in systolic BP and $A G T-6 \mathrm{~A} / \mathrm{G}$ genotype; (4) a nonsignificant trend towards higher systolic $\mathrm{BP}$ in subjects homozygous for $A G T-6 \mathrm{~A} / \mathrm{A}$ than in subjects with the other two genotypes; and (5) a nonsignificant trend towards association between $A G T-6 \mathrm{~A}$ and a diagnosis of hypertension. The levels of significance for the positive associations of phenotypes with $A G T-6 \mathrm{~A}$ were less than those previously reported for AGT T235 in this sample (Hegele et al. 1997). Our findings indicate that the $A G T-6 \mathrm{~A} / \mathrm{G}$ genotype, which marks a genomic variant that has been demonstrated to have in vitro functional relevance, is no more strongly associated with variation in $\mathrm{BP}$ than the $A G T$ codon 235 genotype in this sample. Our findings are consistent with linkage disequilibrium with T235 or another causative variant as the basis for the association of this locus with BP, as opposed to a direct effect of the promoter variant itself on these phenotypes.

Convincing in vitro data suggest that the $A G T-6 \mathrm{G}$ variant preferentially binds a trans-acting factor which leads to net reduction of $\sim 30 \%$ in transcriptional activity (Inoue et al. 1997). While BP was within the physiologic range in the Sandy Lake sample, our findings suggest that the AGT $-6 \mathrm{~A}$ variant, which probably marks the ancestral form of the gene (Inoue et al. 1997) and is functionally different from the $A G T-6 \mathrm{G}$ variant, might be associated with higher BP. However, we cannot resolve the relative significance of either the $A G T-6 \mathrm{~A}$ or T235 variants in this sample. Our hope had been to demonstrate that the marker for altered in vitro expression of $A G T$ would be associated unequivocally with biologically plausible phenotypes. However, our results do not exclude the possibility of linkage with other functionally important DNA changes in $A G T$, whether at codon 235 or elsewhere within the gene or at the locus.

Despite a frequency of $A G T-6 \mathrm{~A}$ of 0.85 , only $40 \mathrm{mem}-$ bers of this study group were prescribed antihypertensive medications. The frequency of the $A G T-6 \mathrm{~A}$ allele in the subset who were taking antihypertensive medications was 0.87 , which was not significantly different from the prevalence of 0.85 seen in the subset who were not taking antihypertensive medications. Also, the frequency of the $A G T-6 \mathrm{~A}$ allele in hypertensive subjects was 0.89 , which was only marginally different from the prevalence of 0.84 in the normotensive subjects. The relatively low incidence of hypertension in this aboriginal study sample despite the very high frequency of the $A G T-6 \mathrm{~A}$ allele may have been related to the relatively young age of the study sample. Alternatively, there may be unique secondary factors in the genetic background of this study sample that could attenuate the development of hypertension that might be associated with the $A G T-6 \mathrm{~A}$ variant.

Analysis of human populations and in primates suggests that both $A G T-6 \mathrm{~A}$ and T235 variants mark the original form of the gene (Inoue et al. 1997). However, linkage disequilibrium between $A G T-6 \mathrm{~A}$ and T235 variants is not as strong in the Sandy Lake Oji-Cree as it is in other human populations. This apparent loss of linkage disequilibrium could have resulted from factors such as recombination over time. There are other attributes suggesting that the Sandy Lake Oji-Cree are genetically unique. For instance, there is a very high $A G T-6 \mathrm{~A}$ allele frequency in Sandy Lake compared to other samples. This might have resulted from founder effects involving the ancestors of the contemporary community. Archaeologic studies suggested that hunter-gatherers inhabited the Sandy Lake region 6000 years ago (Hegele et al. 1997). The current inhabitants of the Sandy Lake region lived a hunter-gatherer subsistence until about 70 years ago. The present community is largely descended from one clan, which established the present reservation. Alternatively, selection pressure from a possible advantage of the allele harboring the $A G T-6 \mathrm{~A}$ and T235 variants may have produced the present allele frequencies.

In summary, we have observed that the presence of the $A G T-6 \mathrm{~A}$ variant tended to be associated with higher systolic BP, but this was not significant. This modest association might have been due to a direct effect of the genetic variation, or to linkage disequilibrium with another functional change at the $A G T$ locus. Variation of $A G T$ may be associated with a predisposition to markedly abnormal phenotypes, such as hypertension, when secondary genetic or environmental factors are present. Understanding the background of genetic predisposition to abnormal phenotypes may be important in native populations, which appear to develop an increased prevalence of metabolic diseases as their lifestyles change.

Acknowledgments We acknowledge the following groups and individuals: the chief and council of the community of Sandy Lake; the Sandy Lake community surveyors; the Sandy Lake nurses; the staff of the University of Toronto Sioux Lookout program; Annette Barnie; Hussain Azouz (AGT promoter genotypes); Teresa Lippingwell; Liling Chan; and the Department of Clinical Epidemiology of the Samuel Lunenfeld Research Institute. This work was supported by grants from the National Institutes of Health (91-DK-01), the Ontario Ministry of Health (\#04307), the Heart and Stroke Foundation of Ontario (\#B3073), and the St. Michael's Hospital Foundation. Dr. Hegele is a Career Investigator (\#CI-2979) of the Heart and Stroke Foundation of Ontario.

\section{References}

Beaudet AL, Tsui L-C (1993) A suggested nomenclature for designating mutations. Hum Mutat 2:245-248

Bloem LJ, Manatunga AK, Tewksbury DA, Pratt JH (1995) The serum angiotensinogen concentration and variants of the angiotensinogen gene in white and black children. J Clin Invest 95:948-953

Bloem LJ, Foroud TM, Ambrosius WT, Hanna MP, Tewksbury DA, Pratt JH (1997) Association of the angiotensinogen gene to serum angiotensinogen in blacks and whites. Hypertension 29:10781082

Hata A, Namikawa C, Sasaki M, Sato K, Nakamura T, Tamura K, Lalouel J-M (1994) Angiotensinogen as a risk factor for essential hypertension in Japan. J Clin Invest 93:1285-1287

Hegele RA, Brunt JH, Connelly PW (1994a) A polymorphism of the angiotensinogen gene is associated with variation in blood pressure in a genetic isolate. Circulation 90:2207-2212

Hegele RA, Evans AJ, Tu L, Ip G, Brunt JH, Connelly PW (1994b) A gene-gender interaction affecting lipoproteins in a genetic isolate. Arterioscler Thromb 14:671-678 
Hegele RA, Brunt JH, Connelly PW (1995a) A polymorphism of the paraoxonase gene associated with variation in blood pressure in a genetic isolate. Arterioscler Thromb Vasc Biol 15:89-95

Hegele RA, Brunt JH, Connelly PW (1995b) Multiple genetic determinants of variation of plasma lipoproteins in a genetic isolate. Arterioscler Thromb Vasc Biol 15:861-871

Hegele RA, Harris SB, Hanley AJG, Sun F, Connelly PW, Zinman B (1997) Angiotensinogen gene variation associated with variation in blood pressure in aboriginal Canadians. Hypertension 29:10731077

Hill WG, Robertson A (1968) Linkage disequilibrium in finite populations. Theor Appl Genet 38:226-231

Inoue I, Nakajima T, Williams CS, Quackenbush J, Puryear R, Powers M, Cheng T, Ludwig EH, Sharma AM, Hata A, Jeunemaitre X, Lalouel J-M (1997) A nucleotide substitution in the promoter of human angiotensinogen is associated with essential hypertension and affects basal transcription in vitro. J Clin Invest 99:17861797
Jeunemaitre X, Soubrier F, Kotelevtsev YV, Lifton RP, Williams CS, Carru A, Hunt SC, Hopkins PN, Williams RR, Lalouel J-M, Corvol P (1992) Molecular basis of human hypertension: role of angiotensinogen. Cell 71:169-180

Kim HS, Krege JH, Kluckman KD, Hagaman JR, Hodgin JB, Bets CF, Jennette JC, Coffman TM, Maeda N, Smithies O (1995) Genetic control of blood pressure and the angiotensinogen locus. Proc Natl Acad Sci USA 92:2635-2639

Rotimi C, Morrison L, Cooper A, Oyejide C, Effing E, Ladipo M, Osotemheninen O, Ward R (1994) Angiotensinogen gene in human hypertension: lack of an association of the T235 allele among African Americans. Hypertension 24:591-594

SAS Institute (1987) SAS/STAT guide for personal computers. SAS Institute, Cary, NC

Williams RR, Hunt SC, Hopkins PN, Hasstedt SJ, Wu LL, Lalouel JM (1994) Finding the genes for human hypertension. In: Woodford FP, Davignon J, Sniderman A (eds) Atherosclerosis X. Elsevier Science, Netherlands, pp 856-861 